Supporting Information

\title{
A two-compartment kinetic modeling of radiocesium accumulation in marine bivalves under hypothetical exposure regimes
}

\author{
Ke PAN ${ }^{\dagger,+}$, Qiao-Guo TAN ${ }^{\S}$, Wen-Xiong WANG ${ }^{*}, \dagger, 末$ \\ ${ }^{\dagger}$ Division of Life Science, The Hong Kong University of Science and Technology \\ (HKUST), Clear Water Bay, Kowloon, Hong Kong \\ ${ }^{\ddagger}$ HKUST Shenzhen Research Institute, Shenzhen 518057, China \\ ${ }^{\S}$ Key Laboratory of the Coastal \& Wetland Ecosystems, Ministry of Education, College of \\ the Environment \& Ecology, Xiamen University, Xiamen, Fujian 361102, China
}

*Corresponding author. Email: wwang@ust.hk

Phone: (852) 23587346; fax: (852) 23581559

Number of pages: 5

Number of Figures: 1 (Figure S1) 


\section{Calculation of the efflux rate constant $\left(k_{\mathrm{e}}\right)$ for the kinetic modeling}

The depuration of ${ }^{137} \mathrm{Cs}$ after 7-day combined exposure of dissolved and dietary ${ }^{137} \mathrm{Cs}$ can be described by a two-compartment loss model (Figure 1). There is no ${ }^{137} \mathrm{Cs}$ influx during the depuration process and no growth was observed after the depuration, thus $J_{\text {in }}(t)=0$ and $g=0$. The depuration of ${ }^{137} \mathrm{Cs}$ in bivalves can be described using equations S1-S3.

$$
\begin{gathered}
C_{\mathrm{int}}(t)=C_{1}(t)+C_{2}(t) \\
\frac{d C_{1}(t)}{d t}=-\left(k_{\mathrm{e} 1}+k_{12}\right) \times C_{1}(t) \\
\frac{d C_{2}(t)}{d t}=k_{12} \times C_{1}(t)-k_{\mathrm{e} 2} \times C_{2}(t)
\end{gathered}
$$

Where $C_{\text {int }}(t)$ is the percentage of ${ }^{137}$ Cs radioactivity remained bivalve at time $t$ (day). At the start of the depuration, $C_{\mathrm{int}}(t)=100 . C_{1}(t)$ and $C_{2}(t)$ are the percentage of ${ }^{137} \mathrm{Cs}$ radioactivity distributed in compartment one and two, respectively. $k_{\mathrm{e} 1}$ is the efflux rate constant of ${ }^{137} \mathrm{Cs}$ from compartment one $\left(\mathrm{day}^{-1}\right) ; k_{\mathrm{e} 2}$ is the efflux rate constant of ${ }^{137} \mathrm{Cs}$ from compartment two $\left(\mathrm{d}^{-1}\right) ; k_{12}$ is the rate constant for ${ }^{137} \mathrm{Cs}$ being transferred from compartment one to two. 


\section{Calculation of the dissolved uptake rate constant $\left(k_{u}\right)$ for the kinetic modeling}

For the aqueous exposure, the influx rate of ${ }^{137} \mathrm{Cs}$ equals to the product of $C_{\mathrm{w}}$ and $k_{\mathrm{u}}$. The accumulation of ${ }^{137} \mathrm{Cs}$ from dissolved phase in the bivalves can be mathematically described as equation S4-S6:

$$
\begin{gathered}
C_{\mathrm{int}}(t)=C_{1}(t)+C_{2}(t) \\
\frac{d C_{1}(t)}{d t}=k_{\mathrm{u}} \times C_{\mathrm{w}}(t)-\left(k_{12}+k_{\mathrm{e} 1}\right) \times C_{1}(t) \\
\frac{d C_{2}(t)}{d t}=k_{12} \times C_{1}(t)-k_{\mathrm{e} 2} \times C_{2}(t)
\end{gathered}
$$

where $C_{\text {int }}(t)$ is the weight-specific radioactivity in bivalve soft tissue (ccpm dry $\left.\mathrm{g}^{-1}\right) \cdot k_{\mathrm{u}}$ is the dissolved uptake rate constant $\left(\mathrm{L} \mathrm{dry} \mathrm{g}^{-1} \mathrm{~d}^{-1}\right)$; and $C_{\mathrm{w}}(t)$ is the ${ }^{137} \mathrm{Cs}$ radioactivity in exposure solution (ccpm L $\left.{ }^{-1}\right) . C_{1}(t)$ and $C_{2}(t)$ are the ${ }^{137} \mathrm{Cs}$ radioactivity (ccpm dry $\mathrm{g}^{-1}$ ) distributed in compartment one and two, respectively. $k_{\mathrm{e} 1}, k_{\mathrm{e} 2}$ and $k_{12}$ were obtained from the efflux experiment. 


\section{Calculation of the assimilation efficiency $(A E)$ for the kinetic modeling}

In the pulse-feeding experiment for measuring $A E$, the ${ }^{137} \mathrm{Cs}$ ingested into the gut of bivalve may be either assimilated into tissues or to be egested in the form of feces (Figure S1). At each time point, the radioactivity remained in a bivalve include assimilated part, $A_{\mathrm{a}}(t)$, and unassimilated part, $A_{\text {gut }}(t)$. During the 48 -h depuration, the unassimilated ${ }^{137} \mathrm{Cs}$ was continuously egested from gut, while the assimilated ${ }^{137} \mathrm{Cs}$ was transferred into compartment one and two, which was then eliminated from bivalve following a two-compartment loss as described above. The absorption of ${ }^{137} \mathrm{Cs}$ from gut and the egestion of unassimilated ${ }^{137} \mathrm{Cs}$ were also assumed to follow the firstorder kinetics. The depuration of ${ }^{137} \mathrm{Cs}$ after ingestion of radiolabelled food can be described using equation S7 to S11.

$$
\begin{aligned}
& A_{\text {int }}(t)=A_{\mathrm{gut}}(t)+A_{\mathrm{a}}(t) \\
& \frac{d A_{\mathrm{gut}}(t)}{d t}=-\left(k_{\mathrm{a}}+k_{\mathrm{f}}\right) \times A_{\mathrm{gut}}(t) \\
& A_{\mathrm{a}}(t)=A_{\mathrm{a} 1}(t)+A_{\mathrm{a} 2}(t) \\
& \frac{d A_{\mathrm{a} 1}(t)}{d t}=k_{\mathrm{a}} \times A_{\mathrm{gut}}(t)-\left(k_{\mathrm{e} 1}+k_{12}\right) \times A_{\mathrm{a} 1}(t) \\
& \frac{d A_{\mathrm{a} 2}(t)}{d t}=k_{12} \times A_{\mathrm{a} 1}(t)-k_{\mathrm{e} 2} \times A_{\mathrm{a} 2}(t)
\end{aligned}
$$

where $A_{\text {int }}(t)$ is the percentage of ${ }^{137} \mathrm{Cs}$ radioactivity remained bivalve at time $t(\mathrm{~h}) . A_{\text {int }}=100$ when $t=0 . A_{\text {gut }}(t)$ is the percentage of ${ }^{137}$ Cs radioactivity remained in the gut of bivalve. $A_{\mathrm{a}}(t)$ is the percentage of assimilated ${ }^{137} \mathrm{Cs}$ radioactivity. $k_{\mathrm{a}}$ is the rate constant $\left(\mathrm{h}^{-1}\right)$ for the assimilated ${ }^{137} \mathrm{Cs}$ transferred from gut into other tissue. $k_{\mathrm{f}}$ is the rate constant $\left(\mathrm{h}^{-1}\right)$ for unassimilated ${ }^{137} \mathrm{Cs}$ egested from gut by feces. $k_{\mathrm{e}}$ is the efflux rate constant $\left(\mathrm{h}^{-1}\right)$ obtained from the efflux experiment. Finally, the AE of ${ }^{137} \mathrm{Cs}$ can be calculated as follow:

$$
A E=\frac{k_{\mathrm{a}}}{k_{\mathrm{a}}+k_{\mathrm{f}}}
$$


Figure S1. Schematic of a two-compartment model to simulate ${ }^{137}$ Cs assimilation and loss after pulse-feeding of radiolabeled algae

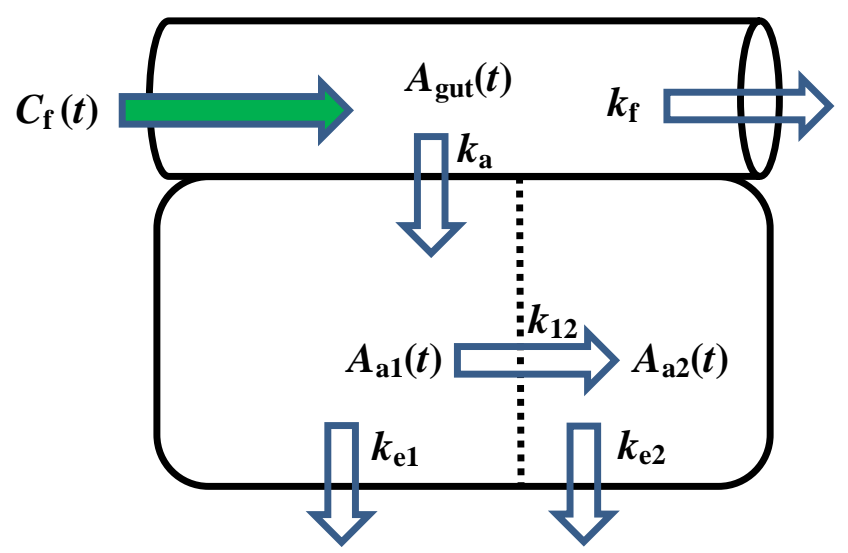

